\title{
Development and application of a loop-mediated isothermal amplification method for rapid detection of Haemophilus parasuis
}

\author{
Jian-Min Zhang ${ }^{1 \#}$, Hai-Yan Shen ${ }^{2 \#}$, Cheng-Gang Xu ${ }^{1}$, Li-Li Guo ${ }^{1}$, Bin Zhang ${ }^{1}$, Jing-Yi Li ${ }^{1}$, Ji- \\ Dang Chen ${ }^{1}$, Hui-Ying Fan ${ }^{1}$ and Ming Liao ${ }^{1 *}$
}

${ }^{1}$ Key Laboratory of Animal Disease Control and Prevention of the Ministry of Agriculture, Key Laboratory of Zoonoses Prevention and control of Guangdong, College of Veterinary Medicine, South China Agricultural University, Guangzhou, People's Republic of China.

${ }^{2}$ The Institute of Veterinary Medicine, Guangdong Academy of Agricultural Sciences, Guangzhou, People's Republic of China.

Accepted 25 March, 2011

\begin{abstract}
Haemophilus parasuis is the causative agent of Glässer's disease that has received much attention recently, due to the increasing economic losses this disease inflicts upon the pig industry worldwide. In this study, loop-mediated isothermal amplification method (LAMP) methodology was designed for diagnosing $H$. parasuis infections and tested against 56 clinical samples. Two sets of primers for LAMP were designed based on the $H$. parasuis inf B gene sequence. Target DNA was amplified and visualized on agarose gels after $50 \mathrm{~min}$ incubation at $63^{\circ} \mathrm{C}$. The LAMP amplicon was also directly visualized in the reaction tubes by the naked eye following the addition of SYBR green I. The detection limit of the inf BLAMP method was $10 \mathrm{cfu} \mathrm{mL}^{-1}$, that was 10 times more sensitive than conventional PCR. Furthermore, positive rates of $H$. parasuis detection using inf B-LAMP were higher $(46.4 \%, 26 / 56)$ than the rates obtained with conventional PCR $(33.9 \%, 19 / 56)$. inf B-LAMP specificity analysis demonstrated no crossreactivity with any other swine pathogens. In conclusion, inf B-LAMP was more sensitive and faster and could be carried out in the absence of expensive equipment. Furthermore, the visual readout demonstrated great potential for the use of inf B-LAMP in the clinical detection of $H$. parasuis.
\end{abstract}

Key words: Glässer's disease, Haemophilus parasuis, inf B, PCR, LAMP

\section{INTRODUCTION}

Haemophilus parasuis is a commensal bacterium that colonizes the upper respiratory tract of domestic pigs and is the causative agent of Glässer's disease. Under appropriate conditions, $H$. parasuis can invade and cause severe systemic disease, characterized by fibrinous

*Corresponding author. E-mail: mliao@scau.edu.cn. Tel: +86020-85280242. Fax: +86-020-85280245.

Abbreviations: LAMP, Loop-mediated isothermal amplification method; PCR, polymerase chain reaction; TSA, tryptic soy agar; EDTA, ethylene diamine tetraacetic acid; NAD, nicotinamide adenine dinucleotide.

\#These authors contributed equally to this work. polyserositis, arthritis and meningitis (Del Rio et al., 2006; Oliveira et al., 2004). The diseases caused by $H$. parasuis have drawn significant attention worldwide (Blackall et al.,1997), with infection rates reaching 50 to $70 \%$ and mortality rates over $10 \%$, leading to substantial economic losses (Baumann et al., 2002). During the past decade, even swine farms with high sanitary standards have experienced a significant increase in the incidence, morbidity and mortality associated with Glässer's disease (Rapp-Gabrielson et al., 2006).

Detection of $H$. parasuis using conventional methods, including culture, biochemical and immunological assays is time-consuming and laborious, typically requiring more than 3 days, although, PCR-based assays have markedly improved the sensitivity and rapidity of $H$. parasuis detection from clinical samples (Ferri et al., 2000). Oliveira 
et al. (2001) established a PCR test based on amplifying the 16S rRNA sequence and evaluated its efficacy on a number of clinical samples and reference strains. Detection of $H$. parasuis by PCR was shown to be more sensitive than culture-based techniques, however, Turni et al. (2009) demonstrated that, real-time PCR designed to amplify 16S rRNA sequence could not differentiate Pasteurella mairii from $H$. parasuis. Fortunately, the inf $\mathrm{B}$ gene is a potential alternative gene target to the $16 \mathrm{~S}$ rRNA gene that was shown to be a useful genetic marker for carrying out phylogenetic studies (Hedegaard et al., 2000). This observation was also true for $H$. parasuis, since the inf $\mathrm{B}$ gene present in this organism has been used to identify $H$. parasuis from all other closely related species (Turni et al., 2009). In addition, the high cost of the instruments required to carry out real-time PCR restricts its use to financially stable clinics and laboratories. Therefore, an affordable, rapid, sensitive and specific $H$. parasuis detection method needs to be developed that will allow a broader range of clinics/laboratories to carry out $H$. parasuis diagnosis. A promising candidate that could full fill these requirements is loop-mediated isothermal amplification (LAMP) (Nagamine et al., 2002a; Notomi et al., 2002b) that amplifies DNA with high specificity, efficiency and rapidity under isothermal conditions. The LAMP assay is faster, more specific and easier to perform than conventional PCR (Nagamine et al., 2002b; Goto et al., 2007; Hara-Kudo et al., 2005) and LAMP results in the synthesis of large amounts of DNA that can be analyzed by agarose gel electrophoresis (Mori et al., 2004; Mori et al., 2001). The successful development of LAMP procedures has been reported for many different clinical applications, including the diagnosis of viral and bacterial infections (Iwamoto et al., 2003; Minami et al., 2006; Song et al., 2005; Wang et al., 2009) and for diagnosis of protozoal diseases, including trypanosomiasis (Kuboki et al., 2003; Thekisoe et al., 2005) and canine and equine piroplasmosis (Alhassan et al., 2007; Ikadai et al., 2004). Although, two LAMP methods have been designed for $H$. parasuis detection, there exist significant differences between them. The LAMP assay developed by Wang et al. (2010) targets the16S rRNA gene, however, the 16S rRNA gene is not species-specific (Turni et al., 2009). For this reason, we choose inf $\mathrm{B}$ as the target gene to established the inf $\mathrm{B}$ LAMP method for the detection of $H$. parasuis. The four specific primers used in our study recognized 6 distinct inf $\mathrm{B}$ target sequences different from those described by Chen et al. (2010). Furthermore, the results of our inf BLAMP method can be evaluated by visualizing color changes with the naked eye after the addition of SYBR green I (Parida et al., 2006), that is, the positive reaction turns green while negative reactions remain orange. Therefore, using the inf B-LAMP assay would increase the probability of diagnosing $H$. parasuis infections in laboratories not equipped with the technology or equipment needed to carry out more labor intensive methodologies such as instrument for PCR or where gel electrophoresis cannot be carried out.

In this study, a specific, sensitive, rapid and simple inf B-LAMP method targeting the inf $\mathrm{B}$ gene of $H$. parasuis was developed. The assay was validated using 56 clinical samples harvested from pigs in herds in south China. This assay provided a powerful $H$. parasuis diagnostic tool which can be applied easily in less well-equipped laboratories, including field conditions.

\section{MATERIALS AND METHODS}

\section{Bacterial strains}

Fifteen (15) reference strains kindly provided by $\mathrm{Dr}$. Chen (Huazhong Agricultural University, China) were used to standardize the LAMP method in this study. Additional strains including Actinobacillus pleuropneumoniae (Serovar 5), A. pleuropneumoniae (Serovar 9), two strains Bordetella bronchiseptica strains, Pasteurella multocida, Streptococcus suis, Salmonella typhimurium and Escherichia coli were used to determine the inf B-LAMP specificity.

\section{DNA extraction}

Template DNA used for inf B-LAMP and PCR were prepared by resuspending individual colonies of respective bacteria grown on tryptic soy agar (TSA) plates in distilled water to a concentration of approximately $1 \times 10^{7} \mathrm{cfu} \mathrm{mL}^{-1}$ and genomic DNA isolated as previously described (Sambrook and Russell, 2001). Bacterial cells were boiled in water for $10 \mathrm{~min}$, centrifuged at $14,000 \mathrm{rpm}$ for 10 min and supernatants then, used as template DNA.

\section{Design of inf B-specific LAMP primers}

To obtain a specific $H$. parasuis gene marker, genome and BLAST analyses were carried out using the National Center for Biotechnology Information server (http://www.ncbi.nlm.nih.gov/). Results showed that, the $H$. parasuis isolate WB24/06-1 translation initiation factor IF-2 (inf B) gene (Gene ID: EF424388) sequence was specific and highly conserved in $H$. parasuis isolates indicating that, inf $\mathrm{B}$ could serve as a potential new candidate gene for the detection of $H$. parasuis. Four primers were designed based on the inf $\mathrm{B}$ gene sequence for use in the LAMP assay and included two outer primers (F3 and B3), one forward inner primer (FIP) and one reverse inner primer (BIP) (Table 1) as previously described (Notomi et al., 2000; Tomita et al., 2008). These primers specifically recognized 6 distinct regions on target DNA (Figure 1). FIP is comprised of the F1c sequence complementary to F1, a TTT linker and the F2 sequence; BIP is comprised of the B1C sequence complementary to B1, a TTT linker and the B2 sequence.

\section{Optimization of the inf B-LAMP conditions}

Final reaction mixtures consisted of $0.8 \mu \mathrm{M}$ each FIP and BIP primers, $0.2 \mu \mathrm{M}$ of each F3 and B3 outer primers, $400 \mu \mathrm{M}$ of each dNTP, $1 \mathrm{M}$ betaine (Sigma, St. Louis, MO, USA), 1X thermopol buffer (New England Biolabs, Ipswich, MA, USA) $2 \mathrm{mM} \mathrm{MgSO}_{4}, 8 \mathrm{U}$ Bst DNA polymerase large fragment (New England Biolabs) and 1 $\mu \mathrm{l}$ genomic DNA ( 100 ng). The optimum temperature and time needed for inf B-LAMP amplification was determined by carrying out reactions in a water bath at $61,62,63,64$ or $65^{\circ} \mathrm{C}$ for 20,30 , 40,50 or $60 \mathrm{~min}$. The reaction was terminated by increasing the 
Table 1. PCR and LAMP primers designed for of the amplification of $16 \mathrm{~S}$ rRNA or info $B$ gene sequences from $H$. parasuis.

\begin{tabular}{ll}
\hline \multicolumn{1}{c}{ Primer } & \multicolumn{1}{c}{ Sequence (5'-3') } \\
\hline P1 & 5'-GTG ATG AGG AAG GGT GGTGT-3' \\
P2 & 5'-GGC TTC GTC ACC CTC TGT-3' \\
F3 & 5'- CGATTGTGGTTGCGGTAAAC-3' \\
B3 & 5'- TAAGATTCGATAACCACACCGC-3' \\
FIP (F1C+ F2) & 5'-GAACATCACCACCGAATTTCTCAGAA TTTTAAACCAGAAGCAAACCCAGAGC-3' \\
BIP (B1C+ B2) & 5'-ATGGGGATTGACGACTTACTTGAAGCTTTCATACCCTCTTTCACTGCACTTAATTC-3' \\
\hline
\end{tabular}

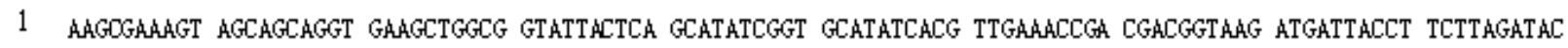

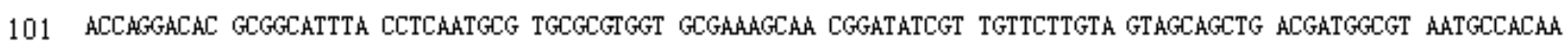

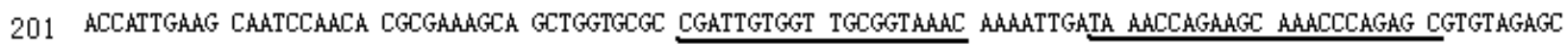

F3

F2

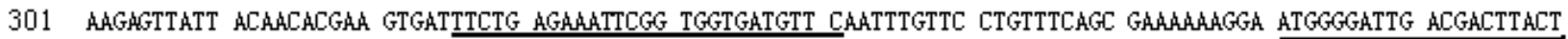

F1

Ble

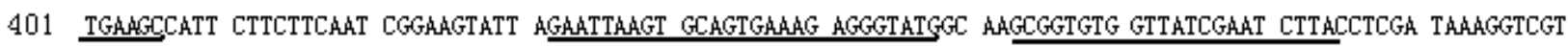

B2c B3

$501 G$

Figure 1. $H$. parasuis inf B gene nucleotide sequence (Gene ID: EF424388) used for primer design. Locations of target primer sequences are underlined.

temperature to $80^{\circ} \mathrm{C}$ for $4 \mathrm{~min}$. A positive control (purified $H$. parasuis DNA) and a negative control (distilled water) were included during each run. LAMP products $(3 \mu \mathrm{l})$ were electrophoresed on $2 \%$ molecular-grade agarose gel prepared in $0.5 \times$ tris-borate-EDTA buffer stained with $0.5 \mathrm{~g} \mathrm{~mL}^{-1}$ ethidium bromide. In addition, the amplification products were visualized following the addition of 1 $\mu$ lof SYBR green I dye to the reaction tube.

\section{PCR conditions}

Conventional PCR designed to target nuclear 16S rRNA gene sequence described by Oliveira et al. (2001) was performed on all bacterial species described for this study. PCR reactions were carried out as follows: $2.5 \mu \mathrm{l} 10 \mathrm{x}$ Ex Taq buffer, $0.2 \mathrm{mM}$ of each dNTP, $0.2 \mu \mathrm{M}$ of each primer (P1 and P2), $0.625 \mathrm{U}$ Ex Taq DNA polymerase (TaKaRa, Dalian, China) and $1 \mu$ l of genomic DNA template adjusted to a final volume of $25 \mu \mathrm{l}$ with $\mathrm{ddH}_{2} \mathrm{O}$. Amplification conditions consisted of an initial denaturation at $94^{\circ} \mathrm{C}$ for 4 min followed by 30 cycles of amplification for $30 \mathrm{~s}$ at $94^{\circ} \mathrm{C}, 30 \mathrm{~s}$ at $59^{\circ} \mathrm{C}, 1 \mathrm{~min}$ at $72^{\circ} \mathrm{C}$ and a final extension for $8 \mathrm{~min}$ at $72^{\circ} \mathrm{C}$. PCR products were subjected to electrophoresis on a $2 \%$ agarose gel.

\section{Sensitivity and specificity of inf B-LAMP and PCR}

To determine the sensitivity of the LAMP assay, 10-fold serial dilutions were made from $1 \times 10^{7} \mathrm{cfu} \mathrm{mL}^{-1} \mathrm{H}$. parasuis stock solutions and compared with PCR results obtained using similar templates at identical concentrations. To determine the specificity of inf B-LAMP, $15 \mathrm{H}$. parasuis reference strains as well as 8 different bacterial strains were tested.

\section{Evaluation of the inf B-LAMP assay using clinical samples}

Fifty-six (56) samples obtained from tonsil, lung and pericardium tissues or from nasal swabs were collected from pigs of 10 farms in south China. Samples were excised and placed in sterile tubes containing $5 \mathrm{ml}$ TSB (containing $10 \mathrm{mg} / \mathrm{ml} \mathrm{NAD}$ and $5 \%$ bovine serum) and incubated for $8 \mathrm{~h}$ at $37^{\circ} \mathrm{C}$ with agitation. Genomic DNA was isolated as described previously. DNA templates $(1 \mu \mathrm{l})$ from each sample were then, used for LAMP and PCR.

\section{RESULTS}

\section{Validation of inf B-LAMP}

LAMP products were detected at 5 different temperatures $\left(61,62,63,64\right.$ and $\left.65^{\circ} \mathrm{C}\right)$ and the best results were obtained when the reaction temperature was maintained at $63^{\circ} \mathrm{C}$ (Figure 2a). To determine the optimum duration 

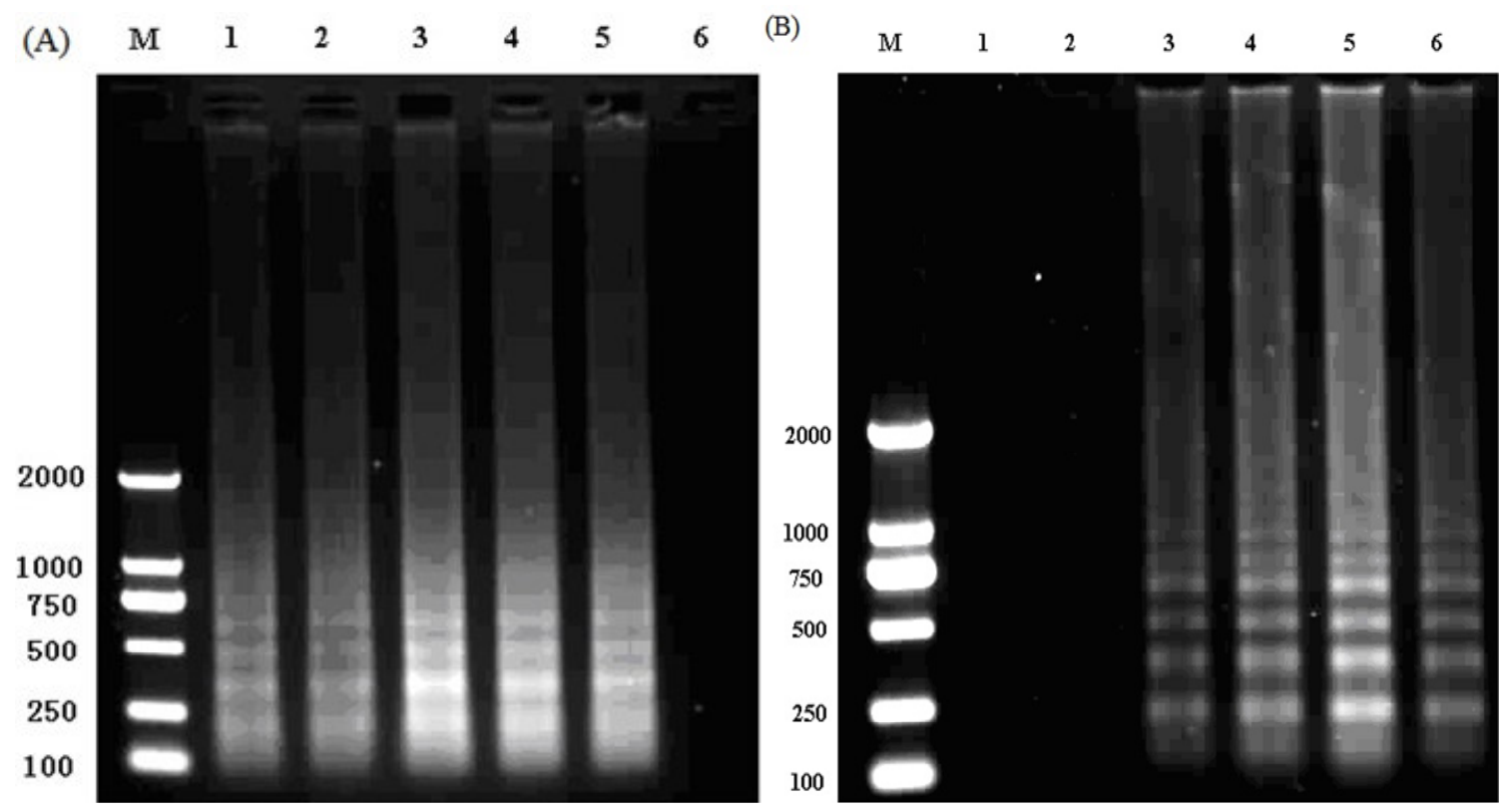

Figure 2. Determination of LAMP conditions at different temperatures $(A)$ or times (B) using 100 ng DNA extracted from $H$. parasuis. (A) Lane M, DNA marker 2000; lanes 1 to 5 , reactions carried out at $61,62,63,64$ or $65^{\circ} \mathrm{C}$ for $50 \mathrm{~min}$, respectively; lane 6 , negative control. (B) Lane M, DNA marker 2000; lane 1, negative control; lanes 2 to 6 , reactions carried out at $63^{\circ} \mathrm{C}$ for $20,30,40,50$, or $60 \mathrm{~min}$, respectively.

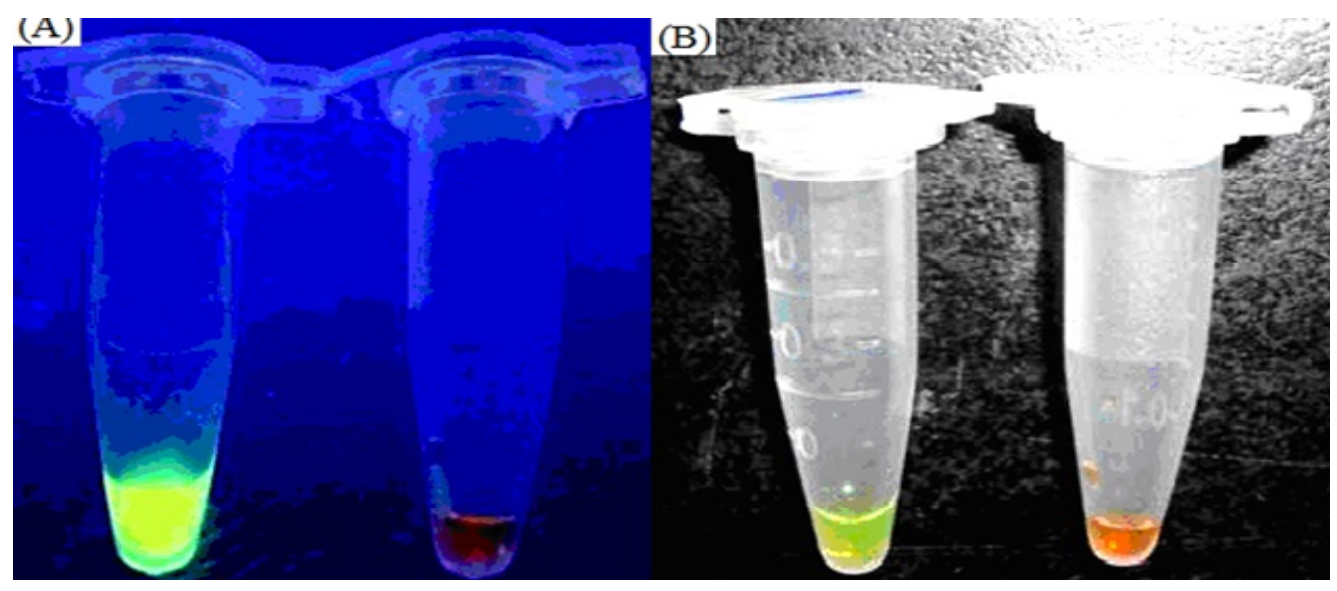

Figure 3. Visual detection of $H$. parasuis inf B gene LAMP reaction using SYBR green I under UV light $(A)$ or white light $(B)$. Plus (+) sign denotes positive reactions (with target DNA) and minus (-) signs denote negative reactions (without target DNA).

of the LAMP assay, LAMP reactions were set up for 5 different incubation times including 20, 30, 40, 50 and 60 $\min$. As shown in Figure 2b, the LAMP amplicon accumulation was observed at five of these times; however, for complete amplification, the $50 \mathrm{~min}$ reaction time was optimal.

\section{Detection of inf B-LAMP and PCR products}

Electrophoresis of LAMP products demonstrated that, all positive LAMP reactions produced the characteristic multiple band ladder and the sizes of the multiple bands were of the anticipated sizes. Furthermore, LAMP results could be evaluated with the naked eye under natural or UV light (Figure 3). Under UV light or daylight, color changes could be visualized with the naked eye following the addition of SYBR green I to the reaction tubes (the positive reaction turned green whereas, the negative one remained orange). These results supported the electrophoresis data. Electrophoresis of PCR products generated an expected single band of 821 base pairs. The sequence 


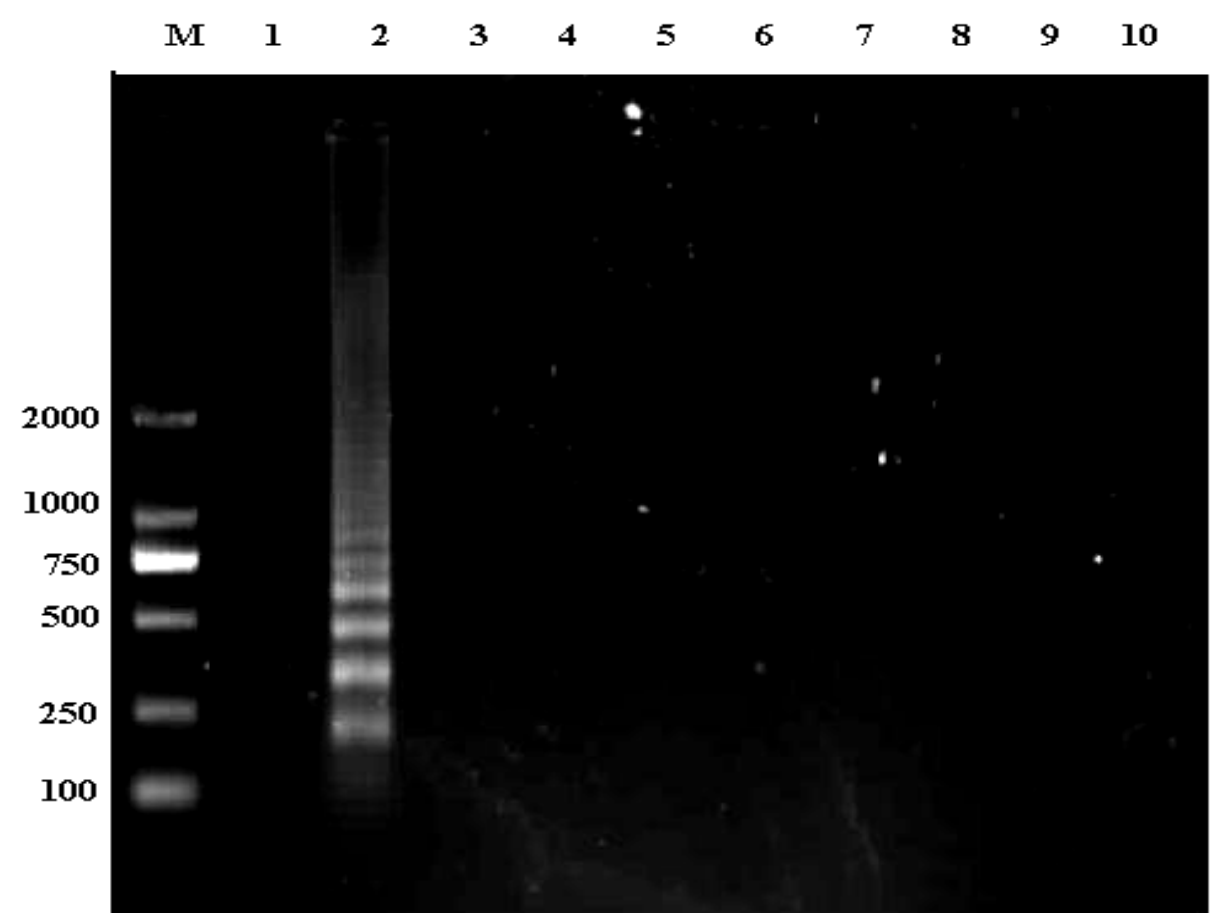

Figure 4. LAMP specificity was confirmed using template DNA extracted from related pathogens. Lane M, DL2000 molecular marker; lane 1, negative control; lane 2, $\mathrm{H}$. parasuis; lane 3, A. pleuropneumoniae (Serovar 5); lane 4, A. pleuropneumoniae (Serovar 9); lane 5, B. bronchiseptica strain 1; lane 6, B. bronchiseptica strain 2; lane 7, P. multocida; lane $8, S$. suis; lane 9, S. typhimurium; lane $10, E$. coli.

of the PCR product showed $100 \%$ identity with the target sequence of $16 \mathrm{~S}$ rRNA gene.

\section{Specificity and sensitivity of inf B-LAMP and PCR}

inf B-specific LAMP accurately detected all 15 reference $H$. parasuis strains but not other bacterial species or the negative (no template) reaction control (Figure 4). The limit of the LAMP assay was $10 \mathrm{cfu} \mathrm{mL}^{-1}$ compared with the $100 \mathrm{cfu} \mathrm{mL}^{-1} \mathrm{PCR}$ assay detection limit (Figure 5) demonstrating that, inf B-LAMP was more sensitive than conventional PCR for detecting $H$. parasuis.

\section{Evaluation of the inf B-specific LAMP assay using clinical samples}

Clinical samples $(n=56)$ were obtained from pigs of 10 farms in south China. Thirteen (13) samples were positive for $H$. parasuis by bacterial isolation, 19 and 26 samples tested positive by PCR and LAMP, respectively. All samples defined as positive by bacterial isolation also tested positive by both PCR and LAMP. All PCR-positive samples were also identified by LAMP (Table 2), however, the LAMP assay demonstrated higher sensitivity than PCR suggesting that, the high specificity and sensitivity of the inf B-LAMP assay was effective in detecting $H$. parasuis from clinical samples.

\section{DISCUSSION}

$H$. parasuis is a non-motile, NAD-dependent, gramnegative bacteria belonging to the family Pasteurellaceae. The fastidious nature of $H$. parasuis hinders its isolation from clinical samples (Oliveira and Pijoan, 2004). In order to reduce the time needed to diagnose $H$. parasuis infections, new techniques will need to be developed. In this study, LAMP was evaluated as a means of diagnosing $H$. parasuis infections using primers designed to target the $H$. parasuis inf $\mathrm{B}$ gene as a means of establishing a sensitive, rapid and specific method for diagnosing $H$. parasuis infections.

The inf $\mathrm{B}$ gene was chosen for this analysis since the 16S rRNA gene sequence is not species-specific, that is, real-time PCR-based technologies designed to amplify $H$. parasuis 16S rRNA were unable to differentiate $H$. parasusis sequences from $P$. mairii (Turni et al., 2009). Hedegaard et al. (2000) reported that, the inf $\mathrm{B}$ gene was a useful genetic marker for phylogenetic studies and this observation was also true for $H$. parasuis. Furthermore, Turni et al. (2009) indicated that the inf $\mathrm{B}$ gene was a suitable target for real-time PCR designed to amplify 

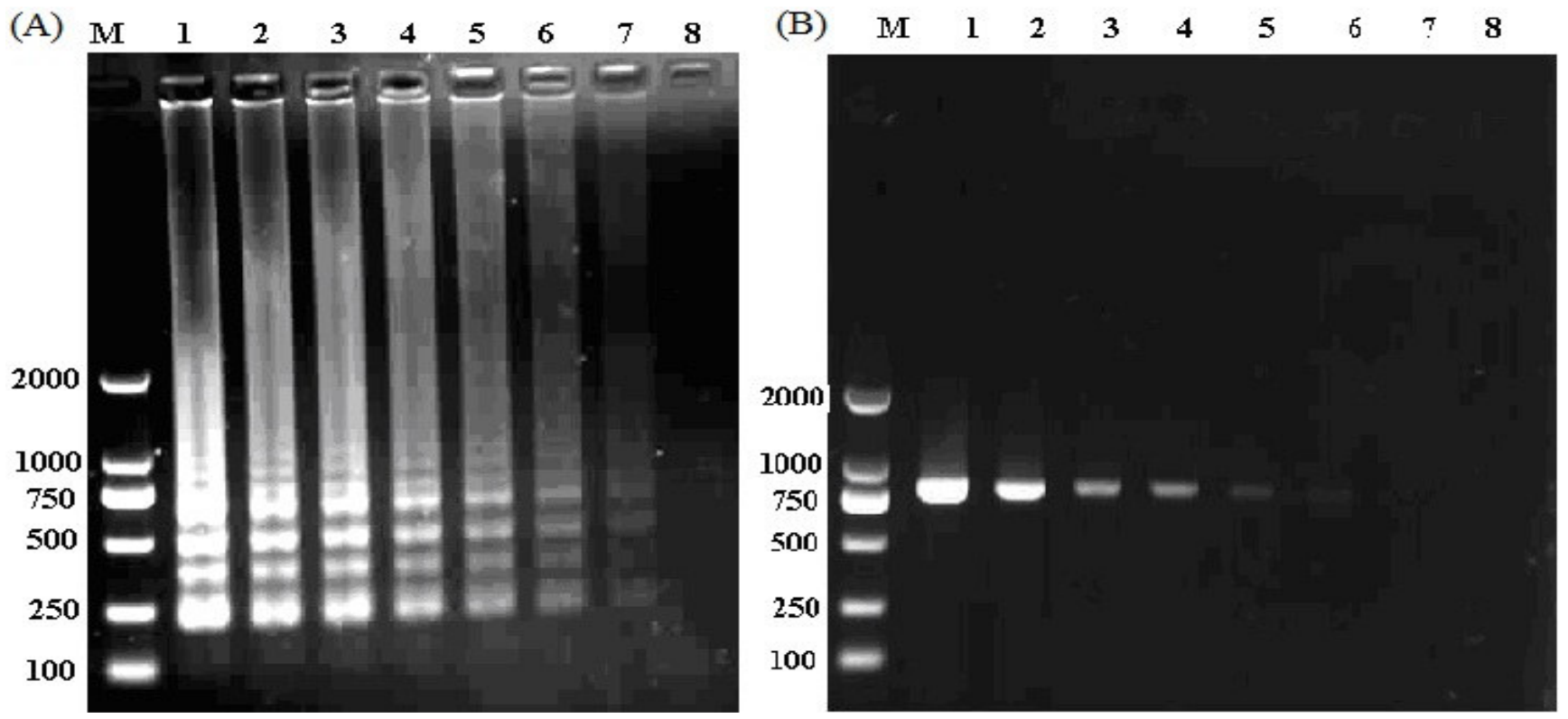

Figure 5. Analytical sensitivity of LAMP and PCR. (A) Sensitivity of LAMP under UV light. Lane M, DL 2000 bp marker; lane 1 to 7,1 $\times 10^{7}, 1 \times 10^{6}, 1 \times 10^{5}, 1 \times 10^{4}, 1 \times 10^{3}, 1 \times 10^{2}$ and $1 \times 10^{1} \mathrm{cfu} \mathrm{mL}^{-1}$ of $H$. parasuis as a template for LAMP (A) or PCR (B) reactions, respectively. Lane 8 , negative control.

Table 2. H. parasuis detection using LAMP, PCR or culture methodologies.

\begin{tabular}{lccc}
\hline & \multicolumn{3}{c}{ Number of positive or negative sample (\% positive or negative) ${ }^{*}$} \\
\cline { 2 - 4 } \multicolumn{1}{c}{ Result } & LAMP & PCR & Bacterial isolation \\
\hline Positive & $26(46.4)$ & $19(34)$ & $13(23.2)$ \\
Negative & $30(53.6)$ & $37(66)$ & $43(76.8)$ \\
\hline
\end{tabular}

*The number in parentheses indicates the percent positive or negative $H$. parasuis isolates identified using the various methodologies $(n=56)$.

$H$. parasuis-specific sequences since it distinguished $H$. parasuis from other closely related species. This observation was confirmed by comparing the $H$. parasuis inf $B$ gene sequence (Gene ID: EF424388) derived from NCBI BLAST with other inf $B$ sequences, revealing that $H$. parasuis inf $B$ was significantly different from the inf $B$ sequence of other species. This demonstrated that, the $H$. parasuis inf B gene was unique and could serve as a genetic marker for phylogenetic studies. In this study, the specificity of inf B-LAMP was examined by demonstrating that, $H$. parasuis inf $B$ sequences did not cross react with inf $B$ sequences from $A$. pleuropneumoniae, $B$. bronchiseptica, P. multocida, S. suis, S. typhimurium or $E$. coli. This analysis demonstrated that, the $H$. parasuis inf $B$ sequence was non-cross reactive with any sequences associated with related pathogens.

$H$. parasuis is a slow-growing, fastidious organism with specific nutritional requirements (Ferri et al., 2000; Oliveira et al., 2004) making its isolation from clinical samples difficult. Therefore, culture methodologies are not sensitive enough for identifying $H$. parasuis. Recently, however, PCR-based methodologies have become attractive diagnostic alternatives. A caveat associated with PCR-based technologies, however, is that amplification of the $H$. parasuis 16 S rRNA PCR can result in a significant number of false positive results due to the high level of similarity between the $H$. parasuis 16S rRNA sequence and the 16S rRNA sequence of related pathogens (Oliveira et al., 2001; Angena et al., 2007). The inf B-LAMP method described here was $H$. parasuis specific and did not produce false positive reactions when tested against the 8 non-target species. According to the sensitivity assay data, inf B-LAMP demonstrated a

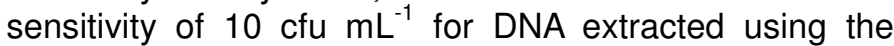
boiling water method. The LAMP reaction was carried out with two sets of specific primers that recognized six distinct sequences on the target inf $\mathrm{B}$ gene. Therefore, it was expected that these primers would amplify the target sequence with high specificity (Notomi et al., 2000; Nagamine et al., 2002a, b). Moreover, the LAMP assay could be performed on-site, using simple and inexpensive experimental set-ups such as a water bath or heat block that provide a constant temperature. In addition, LAMP reaction products can be evaluated with the naked eye by 
examining the color changes following the addition of SYBR green I to the reaction mixture. The positive rate of $H$. parasuis detection using inf B-LAMP was higher than the rates obtained with either PCR or culture methods. Overall, these data indicated that, the inf B-LAMP assay was more sensitive than conventional PCR assays.

In this study, the bacteriologic culture method was not more accurate than conventional PCR; however, inf BLAMP was significantly more sensitive than PCR-based technologies designed to amplify $16 \mathrm{~S}$ rRNA-PCR from clinical samples. Data presented in this report suggested that, inf B-LAMP is likely to enhance the diagnosis efficiency of $H$. parasuis infections, particularly since this technique can be carried out in the field or laboratories unable to carry out more labor intensive and expensive methodologies. Moreover, using inf B-LAMP, we were able to detect $H$. parasuis in different tissues (lung, pericardium, nasal swabs) from clinically infected pigs, further validating the specificity of this method.

The inf B-LAMP protocol described in this study is a sensitive, specific and rapid diagnostic tool designed for diagnosing $H$. parasuis infections. This protocol described will be useful in the detection of $H$. parasuis in low concentrations in tissues biopsied from infected pigs. inf B-LAMP can also be used to confirm the early stages of $H$. parasuis infection when bacterial burdens are relatively low. We recommend that, this technique would be applied routinely in the diagnosis of infections and in $H$. parasuis surveillance on swine farms. This approach will facilitate the identification of bacteria-carrying swine at the early stages of infection allowing containment and treatment protocols to be implemented.

\section{ACKNOWLEDGEMENTS}

We would like to thank Professor Huanchun Chen (College of Veterinary Medicine, Huazhong Agricultural University) for providing $15 \mathrm{H}$. parasuis reference strains. This work was supported by the Program for New Century Excellent Talents in University (Grant no. NCET06-0752), Guangdong Technology Planning Committee (Grant no. 2006B0152, 2009A0201006 and 2009B03083050) and the National Natural Science Foundation of China (Grant No.30800826).

\section{REFERENCES}

Alhassan A, Thekisoe OMM, Yokoyama N, Inoue N, Motloang M Y, Mbati P A, Yin H, Katayama Y, Anzai T, Sugimoto $C$ and Igarashi I (2007). Development of loop-mediated isothermal amplification (LAMP) method for diagnosis of equine piroplasmosis. Vet. Parasitol. 143: $155-160$.

Angena O, Oliveira S, Ahrens P, Svensmark B, Leser TD (2007). Development of an improved species specific PCR test for detection of Haemophilus parasuis. Vet. Microbiol. 119: 266-276.

Baumann G, Bilkei G (2002). Effect of vaccinating sows and their piglets on the development of Glässer's disease induced by a virulent strain of Haemophilus parasuis serovar 5. Vet. Rec. 151: 18-21.

Blackall PJ, Trott DJ, Rapp-Gabrielson V, Hampson DJ (1997). Analysis of Haemophilus parasuis by multilocus enzyme electrophoresis. Vet. Microbiol. 56: 125-134.

Chen HT, Chu YF, Liu YS, Zhang J, Lu ZX (2010). Loop-mediated isothermal amplification for the rapid detection of Haemophilus parasuis, FEMS. Immunol. Med. Microbiol. 60: 283-285

Del Rio ML, Navas J, Martin AJ, Gutierrez CB, Rodríguez-Barbosa Jl, Rodríguez Ferri EF (2006). Molecular characterization of Haemophilus parasuis ferric hydroxamate uptake (fhu) genes and constitutive expression of the FhuA receptor. Vet. Res. 37: 49-59.

Ferri EFR, Gutierrez CB, De La Puente VA, Garcia del Blanco N, Navas J, Paniagua ML, del Rio ML, Monter JL (2000). Bacterial meningitis in pigs: Glässer's disease. Porci, 59: 43-60.

Goto M, Hayashidani H, Takatori K, Hara-Kudo Y (2007). Rapid detection of enterotoxigenic Staphylococcus aureus harbouring genes for four classical enterotoxins, SEA, SEB, SEC and SED, by loop-mediated isothermal amplification assay. Lett. Appl. Microbiol. 45:100-107.

Hara-Kudo Y, Yoshino M, Kojima T, Ikedo M (2005). Loop-mediated isothermal amplification for the rapid detection of Salmonella. FEMS Microbiol. Lett. 253:155-161.

Hedegaard J, Hauge M, Fage-Larsen J, Mortensen K, Kilian M, Sperling-Petersen U, Pousen K (2000). Investigation of the translation-initiation factor IF2 gene, inf $\mathrm{B}$, as a tool to study the population structure of Streptococcus agalactiae. Microbiology 146: 1661-1670

Ikadai $\mathrm{H}$, Tanaka $\mathrm{H}$, Shibahara N, Matsuu A, Uechi M, Itoh N, Oshiro S, Kudo N, Igarashi I, Oyamada T (2004). Molecular evidence of infections with Babesia gibsoni parasites in Japan and evaluation of the diagnostic potential of a loop-mediated isothermal amplification method. J. Clin. Microbiol. 42: 2465-2469.

Iwamoto T, Sonobe T, Hayashi K (2003). Loop-mediated isothermal amplification for direct detection of Mycobacterium tuberculosis complex, M. avium, and M. intracellulare in sputum samples. J. Clin. Microbiol. 41: 2616-2622.

Kuboki N, Inoue N, Sakurai T, Di Cello F, Grab DJ, Suzuki H, Sugimoto C, Igarashi I (2003). Loop-mediated isothermal amplification for detection of African trypanosomes. J. Clin. Microbiol. 4: 5517-5524.

Minami M, Ohta M, Ohkura T, Ando T, Torii K, Hasegawa T, Goto H (2006). Use of a combination of brushing technique and the loopmediated isothermal amplification method as a novel, rapid, and safe system for detection of Helicobacter pylori. J. Clin. Microbiol. 44: 4032-4037.

Mori Y, Kitoa M, Tamita N, Notomi T (2004). Real-time turbidimetry of LAMP reaction for quantifying template DNA. J. Biochem. Biophys. Methods 59: 45-157.

Mori Y, Nagamine K, Tomita N and Notomi T (2001). Detection of loopmediated isothermal amplification reaction by turbidity derived from magnesium pyrophosphate formation. Biochem. Biophys. Res. Commun. 289: 150-154.

Nagamine K, Hase T, Notomi T (2002a). Accelerated reaction by loopmediated isothermal amplification using loop primers. Mol. Cell Probes, 16: 223-229.

Nagamine K, Kuzuhara Y, Notomi T (2002b). Isolation of single-stranded DNA from loop-mediated isothermal amplification products. Biochem. Biophys. Res. Commun. 290: 1195-1198.

Notomi T, Okayama H, Masubuchi H, Yonekawa T, Watanabe K, Amino $\mathrm{N}$, Hase T (2000) Loop-mediated isothermal amplification of DNA. Nucleic Acids Res. 28: 63.

Oliveira S, Galina L, Pijoan C (2001). Development of a PCR test to diagnose Haemophilus parasuis infections. J. Vet. Diagn. Invest. 13: 495-501

Oliveira S, Pijoan C (2004). Haemophilus parasuis: new trends on diagnosis, epidermiology and control. Vet. Microbiol. 99: 1-12.

Parida MM, Santhosh SR, Dash PK, Tripathi NK, Saxena P, Ambuj S, Sahni AK, Lakshmana Rao PV, Kouichi Morita (2006). Development and Evaluation of Reverse Transcription-Loop-Mediated Isothermal Amplification Assay for Rapid and Real-Time Detection of Japanese Encephalitis Virus. J.Clin. Microbiol. 44: 4172-4178.

Rapp-Gabrielson V, Oliveira SR, Pijoan C (2006). Haemophilus parasuis. In: Straw, B., Zimmerman, J.J., D'Allaire, S., Taylor, D.J. (Eds.), Diseases of Swine. Blackwell Publishing, Williston, FL, USA, pp. $681-690$. 
Sambrook J, Russell D (2001). Molecular Cloning: A Laboratory Manual, 3rd ed. Cold Spring Harbor Laboratory Press, Cold Spring Harbor, NY.

Song T, Toma C, Nakasone N, Iwanaga M (2005). Sensitive and rapid detection of Shigella and enteroinvasive Escherichia coli by a loopmediated isothermal amplification method. FEMS Microbiol. Lett. 243: 259-263.

Thekisoe OMM, Inoue N, Kuboki N, Tuntasuvan D, Bunnoy W, Borisutsuwan S, Igarashi I, Sugimoto C (2005). Evaluation of loopmediated isothermal amplification (LAMP), PCR and parasitological tests for detection of Trypanosoma evansi in experimentally infected pigs. Vet. Parasitol. 130: 327-330.

Tomita N, Mori Y, Kanda H, Notomi T (2008). Loop-mediated isothermal amplification (LAMP) of gene sequences and simple visual detection of products. Nat. Protoc. 3: 877-882.

Turni C, Pyke M, Blackall PJ (2009). Validation of a real-time PCR for Haemophilus parasuis. J. Appl. Microbiol. 108: 1323-1331.
Wang Y, Chen P, Guo HB, Chen Y, Liu H, He QG (2009). Loop-mediated is othermal amplification targeting the apxIVA gene for detection of Actinobacillus pleuropneumoniae. FEMS. Microbiol. Lett. 300:83-89.

Wang Y, Fang Y, Liu YY, Chen P, Li WT, Liu SQ, Zou HY, He QG (2010). Development and evaluation of loop-mediated isothermal amplification for rapid detection of Haemophilus parasuis. FEMS. Microbiol. Lett. 333: 54-60. 